\title{
The Persistence Of Sexual Discrimination In The Workplace
}

Paul A. Swanson (Email: swansonp@wpunj.edu), William Paterson University

\begin{abstract}
Measured by an increasing labor force participation rate for women, a falling dissimilarity index for occupational sex segregation, and a declining male/female earnings gap, there has been increasing integration of women into the workforce in the U.S. over the last fifty years. This increased diversity should lead to increased productivity, thus inducing profit-maximizing firms to encourage it. However, sexual segregation has persisted for so long that it must be beneficial for the capitalist system as a whole. By keeping women separate and subservient with lower wages than men, firms exploit sexual discrimination and are able to maintain higher profits.
\end{abstract}

\subsection{Introduction}

W

omen have become increasingly involved in the workforce in the United States over the last 50 years. As measured by labor force participation rates, by occupational segregation, and by the gap in earnings between women and men, women are becoming an ever more significant part of the labor force. And yet, even with this increasing involvement, women seem to still be left behind in many ways.

Given these trends, one might suppose that continuing discrimination is merely a residual, left over from a previous era, and would eventually disappear completely. Economic forces within capitalism should eliminate sexual discrimination as firms compete against one another in their drive to maximize profits. However, sexual discrimination is still so manifest that this supposition is suspect. Why has discrimination lasted for so long? Is there any economic force that helps perpuate the subordination of women? Do firms benefit by discriminating against women?

\subsection{Sex Segregation and the Pay of Women}

It is well known that the labor force participation rate of women has increased significantly over the past 50 years in the U.S. Figure 1 shows that this rate increased $77.6 \%$ (from $33.9 \%$ to 60.2\%) from 1950 to 2000, while for men the rate dropped $13.5 \%$ (from $86.4 \%$ to $74.7 \%$ ). From being a distinct minority of $29.6 \%$ of the labor force that they were fifty years ago, women have entered the labor force in ever greater numbers so that their attachment to the working world is now nearly equal to that of men, with women constituting $46.6 \%$ of the labor force [Bureau of Labor Statistics, 2002]. According to the Bureau of Labor Statistics, this near equality will continue for the foreseeable future, with women becoming $47.8 \%$ of the labor force by 2025 [Fullerton 1999, p. 4]. Along this dimension, at least in the aggregate, the work place is becoming more diverse.

Does this mean, however, that women are being integrated into occupations--matching the increase in their labor force participation rate--so that they work side by side with men at all levels in most occupations, while receiving equal compensation for their work? Or is there still significant sex segregation both between and within occupations, with a gender gap in wages still remaining? To the extent that the answer to the latter question is in the affirmative, the increase in diversity is illusory.

\section{Readers with comments or questions are encouraged to contact the author via email.}


FIGURE 1: Labor Force Participation Rates (\%)

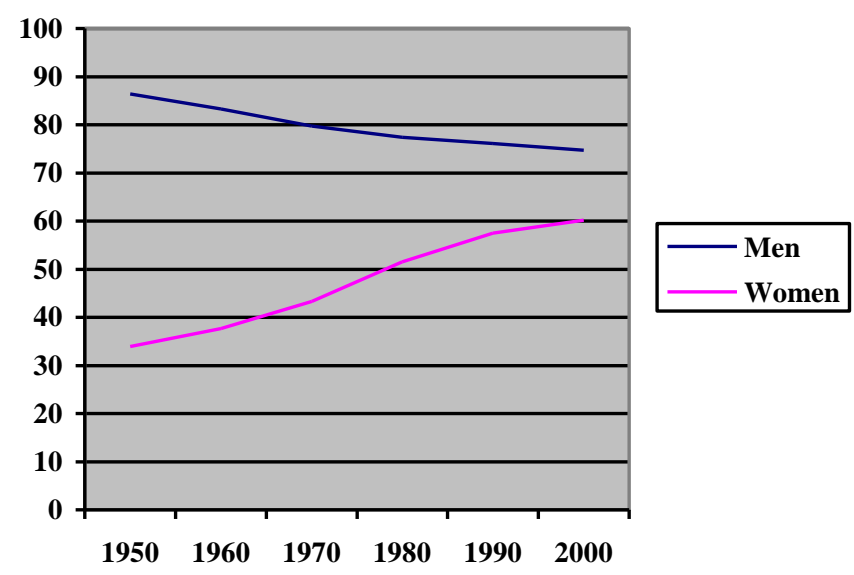

Sources: For 2000, Bureau of Labor Statistics website [www.bls.gov /emp/emplab1.htm]. For all other years, Fullerton [1999, p. 4].
A good measure of occupational segregation by sex is the widely-used Duncan index of dissimilarity [Duncan and Duncan 1955]. This gives a number between 0 and 100, derived from the formula $\mathrm{D}=$ $\sum\left|\frac{f_{i}}{f_{T}}-\frac{m_{i}}{m_{T}}\right| 100$ 2

equal the number of females and males, respectively, in occupation $\mathrm{i}$ and $f_{T}$ and $m_{T}$ equal the total number of females and males, respectively. This index can be interpreted as the percentage of all females (males) who would have to change occupations so that the occupational distributions of females and males would be equal. If this index were 0 there would be perfect equality between the two distri-butions, while if it were 100 all occupations would be either exclusively female or exclusively male.

From 1950 to 2000 , while the labor force participation rate of women was rising from $33.9 \%$ to $60.2 \%$, and the female proportion of the labor force rose from $29.6 \%$ to $46.6 \%$, the index of dissimilarity fell from 67.3 to 52.1 (see Table 1). This means that as women were working in ever greater numbers, they were also becoming somewhat more integrated into the work force. The $22.9 \%$ drop in D from 67.6 to 52.1 which occurred from 1970 to 2000 is not insignificant. The index of 52.1, on the other hand, while probably lower than at any time during the twentieth century (see Goldin 1990, pp. 75-76), is still quite significant, indicating that more than half of all working women in 2000 would have to change occupations to bring about full integration by occupation.

TABLE 1: Index of Dissimilarity

\begin{tabular}{lllll}
1950 & 1970 & 1980 & 1990 & 2000 \\
\hline 67.3 & 67.6 & 59.8 & 56.0 & 52.1
\end{tabular}

Sources: For 1950-1980, Jacobs [1988, p. 170]. The indexes for 1990 and 2000 were calculated from the Current Population Survey [Bureau of the Census, 2001], using 514 occupations for 1990 and 488 occupations for 2000.

The integration of women into the labor force can also be looked at by examining the gender gap in earnings, defined as the ratio of the median earnings of all women to the median earnings of all men. A substantial gap in earnings between men and women would indicate that women are not being accepted into the workplace on a par with men, i.e., women are not being integrated into the labor force. Whether the reason for low earnings be segregation by occupation, or through making it difficult for women to advance within an occupation, or "pure" discrimination, whereby women are paid less for doing the exact same job, a gender gap in earnings would be clear evidence that men and women lead separate lives at work. 


\section{FIGURE 2: The Gender Gap in Earnings}

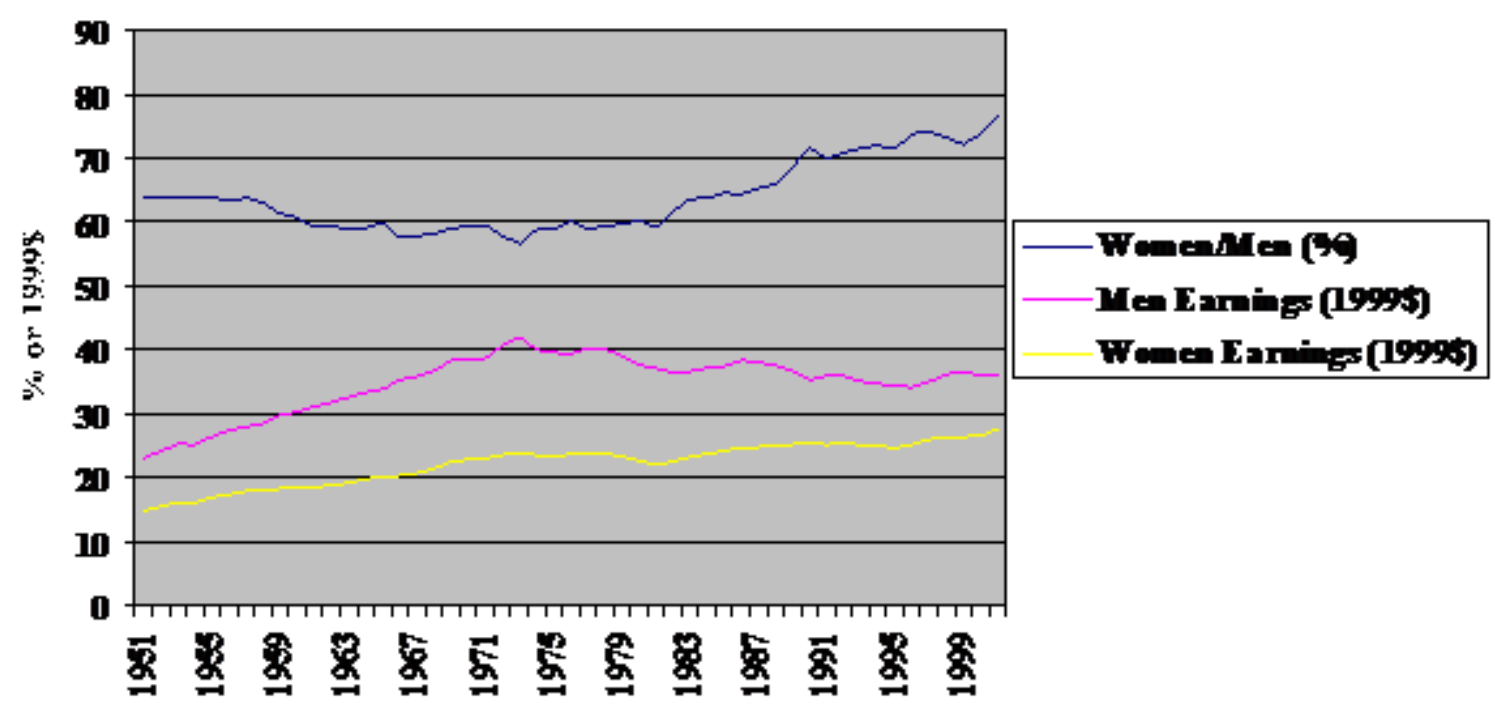

Source: Women's Bureau [2000]. Earnings are median annual in 1999 dollars for year-round full-time workers.

Figure 2 shows the gender gap in earnings, starting in 1951. The percentage of female to male earnings fell fairly continuously until it reached a low of $56.6 \%$ in 1973. It then increased regularly, surpassing the 1951 figure in 1985, reaching a post-War high of 76.3\% in 2001. The significant narrowing of the gender gap since 1973 has occurred statistically because of an increase in women's real earnings coupled with an unfortunate decrease in men's earnings. We will not examine why these earnings moved closer together, but regardless of the underlying causes, the smaller difference between men's and women's earnings shows that women's pay is catching up with men's and thus women are becoming more integrated into the work place. It is worth noting, however, that women still earn only about three-quarters of what men do for full-time work across all occupations.

All of the statistics examined here exhibit the same trend. Since 1950 there has been an increase in the labor force participation rate of women, meaning that women are more attached than ever to the work force. Concurrent with this, there have been a decrease in the index of dissimilarity and an increase in the ratio of women's to men's earnings, both indicating that women are becoming more integrated into the work force in real and significant ways. Although the trend is toward women participating more fully in the work world, it should be emphasized that an index of dissimilarity of 52.1 and an earnings ratio of $76.3 \%$ are still far away from what they would be in a completely integrated workforce.

\subsection{Diversity in the Labor Force}

Diversity should be seen as morally good in and of itself, without regard to profits. That is, more diversity should be seen as ethically preferable to less diversity. Following Rawls, the general conception of distributive justice requires that all social primary goods, such as the liberties of citizenship, income, wealth, and opportunity, be distributed equally, unless an unequal distribution is to the benefit of the least advantaged [Rawls 1971, p. 303]. Since virtually no occupation has demands that favor one sex over the other, equality of opportunity would generate a maximally-diverse labor force, i.e., the result of equal opportunity would be that both men and women would participate equally in the labor force, assuming equal preferences for work on the part of men and women. With a 
diverse labor force in this way being a proxy for equal opportunity (a principle of distributive justice), it would seem that more diversity is better than less diversity.

Given that approximately one-half of those who are working-age are women, maximum diversity would be reached with an even split between men and women. This would mean that every region, every occupation, every firm, and, in fact, every relevant group of workers would be $50 \%$ female. We saw above that, while this is not the case currently in the U.S., the trend is in that direction: there has been a fairly steady increase in women's participation in, and integration into, the labor force over the past 30 years. From a moral standpoint this development is unambiguously good.

For firms in the U.S. today the increasing integration of women into the labor force would appear to be inevitable. For whatever reasons, women's preference for work and the social acceptance of it, along with the support of the legal system for diversity, have all been increasing. Thus, while it may be possible for a single firm to resist hiring women, the social and legal pressures are such that most firms have found it necessary to hire more women over time. Also the fact that more and more women are working, as was documented in the previous section, makes it inevitable that most firms would employ more women, thus increasing the diversity of their work force.

Firms at an individual level should be able to exploit this increased diversity to their own advantage. There are two distinct reasons why this would happen. First, a larger pool of potential workers (in this case, by adding women, the pool essentially doubles) would be to the benefit of employers. The average skill level of those that they would be able to hire would be greater, leading to a more productive workforce, therefore increasing the profit rate.

It may even be true that an individual firm would have to pay less for these more productive workers. Since women tend to be paid less than men, a firm that replaces men with women might end up paying lower wages than before, thereby widening their profit gap over their rivals. Also, the increased supply of labor itself should decrease wages that employers need to pay. This might not reduce the wages of men (although it certainly is possible that it would), but the women coming into the labor market would undoubtedly be forced to accept lower wages. From the viewpoint of an employer, this is an ideal situation--lower wages for more productive workers--and for those firms that do increase their sexual diversity it is a sure way to increase their competitive advantage over rival firms.

The ultimate implication of this is that competitive markets should lead to less discrimination of all types in hiring practices. Since it is more profitable for an individual firm to increase its pool of potential workers by hiring women (and all other groups that have been historically discriminated against), most firms would eventually follow suit. The fact that sexual discrimination (as well as many other types of discrimination) has existed in the U.S. for a long time, and is still significant today, must mean that other factors are operating in the opposite direction. But from this perspective, at least, competitive pressures would push the economy toward a discrimination-free position.

Firms would also be able to exploit increased diversity to their advantage even if it did not result in a larger pool of potential workers. In the first argument we assumed that women were as productive as men on average. Thus the pool of workers at any level of productivity would double so that employers would not have to dip as deeply into the total pool to acquire as many workers as they had before. Overall productivity in the individual firms would thereby increase. It may also be true, however, that diversity itself would increase overall productivity, apart from any increase due to a larger pool of workers. In addition to the usual sort of productivity ascribable to both women and men, women may bring a different sort of productivity to the workplace, that when combined with the productivity of men, increases total efficiency within the workplace (for a discussion of this point see Cox and Blake [1991]).

\subsection{The Persistence of Sexual Discrimination}

We now address the question of why sexual discrimination has continued to last for so long. We saw above that competitive pressures should help to eliminate discrimination: firms that didn't initially hire women would be at a productive disadvantage, forcing them to eventually follow their competition or go out of business. Since sexual 
discrimination is still significant, however, it must be true that there are other forces at work that maintain discrimination.

One possible explanation for continuing sexual discrimination is the influence of patriarchal conventions on economic relationships. Strober [1984, p. 147] argues that "male employers are not simply profit maximizers," but are also "pursuing ... the maintenance of male privilege." This means that a firm will not hire women for certain jobs so that they can keep women subordinate, thus maintaining the system of patriarchy in the workplace, while also maintaining it in the household. The goal of keeping women subordinate may conflict with profit maximization, so that "male managers are [sometimes] willing to sacrifice some potential profits by allowing men to choose the jobs they wish [Strober 1984, p. 148]." The attempt by male workers to maximize their economic gain takes precedence over the attempt by firms to maximize profits. Reskin [1988, p. 61] argues along similar lines, attributing the income gap between men and women to men's ability "to preserve their advantage position ... by distribut[ing] valued resources in their favor." The central actors in these decisions are not firms, as would be expected in a capitalist economy, but rather men, in their capacity as either employers or workers, who want to maximize their advantage vis-à-vis women.

While patriarchal relationships may have some influence on the behavior of firms, it is difficult to see how or why males would perpetuate their advantage at the expense of profitability. Certainly there is some leeway in profit maximization and firms do not always have to be at the maximum point. Other factors, such as power, patriarchy, or prestige, can influence their decisions, along with profitability. But it would seem that profitability would generally be the driving factor, with those firms that make more pushing out those that make less. Especially at the economy-wide level, profitability is what dominates decision-making, and patriarchy would be influential only if it contributed to this goal. The attempt by male managers to maintain patriarchy by itself cannot be the most significant reason for the persistence of sexual discrimination.

As is obvious from the data on sexual segregation, women can be considered a distinct group in the U.S. economy. Their attachment to the labor force, their position within firms, and their average wage all point to a separateness from men. Can this aspect of patriarchy be used by firms to increase profits? If firms can use this to keep women's wages low then the answer is clearly yes. Here is where, with a slight change, Strober's argument can be applied. It is not that patriarchy is a goal in and of itself, but rather it is that firms can use patriarchy to increase profits by restricting the advancement of women. By reinforcing patriarchal norms and keeping women separate, firms are able to ensure that women's earnings are kept below those of men.

It may be possible for renegade firms to increase their individual profits by hiring more talented women at slightly higher wages (but still below what they would pay to men), thus breaking down the patriarchal system to some extent. This would increase their productivity without a corresponding increase in costs, and if it became widespread, competitive pressures would indeed eliminate the segregation of women in the workplace and therefore this one aspect of patriarchy. But if segregation were to diminish too much, women's wages would increase until there was no longer a significant gender gap in earnings. The advantage to firms as a whole would be gone. Since this is not the case, there must be forces countering these individual firms that attempt to reduce patriarchy.

Reich, Gordon, and Edwards [1973] have argued that restricting men and women to certain jobs reproduces capitalist hegemony by dividing and conquering the labor force. Like racism, occupational segregation will forestall potential movements uniting workers against capitalists with the happy result that wages are kept low and workers' power is kept in check. In line with Strober and Reskin, they argue that sex differentiation (men and women not working together as equals) leads to a devaluation of women's jobs and enhances male dominance: firms exploit feelings of male superiority to hold women back.

Whereas Reich, Gordon, and Edwards emphasize the control function of labor market segmentation (including sexual occupational segregation) I would change the emphasis and argue that patriarchy serves profitability, rather than conflicting with it (as in Strober and Reskin), and hence is supported by the system as a whole. Male attempts at patriarchy generally increase profits by keeping women's wages low, generating systemic 
forces supporting patriarchy. There will always be a tension between individual firms and firms as a whole, with some of the former trying to subvert the general norms by treating women more equally, but apparently some sort of equilibrium with significant sexual segregation is reached at any given point in time.

\subsection{Conclusions}

Measured by an increasing labor force participation rate for women, a falling dissimilarity index for occupational sex segregation, and a declining male/female earnings gap, there has been increasing integration of women into the workforce in the U.S. over the last fifty years. This promising trend, however, must be tempered by the fact that women still have a long way to go to catch up with men.

This increased diversity should lead to increased productivity, thus inducing profit-maximizing firms to encourage it: individual firms would certainly be pushed toward more diversity by competitive pressures. But since sexual segregation has persisted for so long it must be beneficial for firms as a whole. Keeping women separate enables firms to keep them subservient, thus helping to prevent women's wages from rising and helping firms to retain high profits. Thus capitalists exploit sexual discrimination in order to maintain higher profits (and control, which also leads to higher profits). While there are pressures to reduce discrimination, its function is important enough that counter-pressures achieve a (moving) equilibrium where women remain at a significant disadvantage.

\section{References}

1. Bureau of the Census. Current Population Surveys, March 1962-2001 [machine-readable data files]/conducted by the Bureau of the Census for the Bureau of Labor Statistics. Washington: Bureau of the Census [producer and distributor], 1962-2001. Santa Monica, CA: Unicon Research Corporation [producer and distributor of CPS Utilities], 2001.

2. Bureau of Labor Statistics. [www.bls.gov/emp/emplab1.htm]. Last modified August 29, 2002.

3. Cox, Taylor H., and Stacy Blake. Managing Cultural Diversity: Implications for Organizational Competitiveness. Academy of Management Executive 5, 1991.

4. Duncan, Otis and Beverly Duncan. A Methodological Analysis of Segregation Indexes. American Sociological Review 20, April 1955, pp. 210-217.

5. Fullerton, Howard N. Labor Force Participation: 75 Years of Change, 1950-98 and 1998-2025. Monthly Labor Review 122, No. 12, December 1999, pp. 3-12.

6. Goldin, Claudia. Understanding the Gender Gap. New York: Oxford University Press, 1990.

7. Jacobs, Jerry. Long-Term Trends in Occupational Segregation by Sex. American Journal of Sociology 95, No. 1, July 1989, pp. 160-173.

8. Rawls, John. A Theory of Justice. Cambridge, Massachusetts: Harvard University Press, 1971.

9. Reich, Michael, David M. Gordon, and Richard C. Edwards. A Theory of Labor Market Segmentation. The American Economic Review 63, No. 2, May 1973, pp. 359-365.

10. Reskin, Barbara F. Bringing the Men Back In: Sex Differentiation and the Devaluation of Women's Work. Gender and Society 2, No. 1, March 1988, pp. 58-81.

11. Strober, Myra H. Toward a General Theory of Occupational Sex Segregation: The Case of Public School Teaching. In Sex Segregation in the Workplace, Barbara F. Reskin, ed., Washington, DC: National Academy Press, 1984, pp. 144-156.

12. Women's Bureau. Median Annual Earnings in Current and 1999 Dollars for Year-Round Full-Time Workers by Sex, 1951-99. Published October 2000. [www.dol.gov/wb/wb_pubs/achart.htm] 